are either stationary or ingravescent, and there are hints of circulatory failure such as faint cyanosis, increase in the size of the liver, puffiness under the eyes, and so forth. Fever, then, is not an infallible guide in the treatment of this disease. In search for some other guide Dr. Perry has made an extensive inquiry into the value of leucocyte counts, but here again we have been disappointed, as I have already said. It will be seen, therefore, that we find it impossible to lay down any rules as to the duration of rest in bed in this disease. What $I$ would suggest is that any febrile event of more than four days' duration indicates a subsequent rest of not less than four weeks. Return to activity after this must be gradual and tentative, and conditioned not only by what has happened during the period of rest, but also by the child's response to increasing exercise.

About the use of salicylates there is a wide diversity of opinion. It is useless to weigh the pros and cons here, for the evidence is so misty and inconclusive. My belicf is that it is practically always safe to give salicylates in big doses. Occasionally-in perhaps one case in a hundred-you find that it is doing harm, and then, of course, it must be stopped. Often it will be found that it is not doing good. Sometimes this is because the dose is too small, and sometimes again it is worth while to substitute some other preparation-for example, aspirin may suit a particular child better than the sodium salt. We find that 5 to 10 grains of the former, or 10 to 20 grains of the latter, seldom cause toxic symptoms, even if given every hour or two hours for more than a day at a time. We have tried all sorts of other plans designed to kill off the infection, for this, I suppose, is the way in which the salicylates act; but we have not found anything that can be proved to have the desired effect, and I am not going to weary you with a catalogne of our failures.

Similarly, we have experimented with many means of cnhancing the child's resistance, without much success. I feel sure that when the periods of rest are conjoined with free access to fresh air and sunlight, and with a liberal diet in which fats are given generously, the child gets on better. We have lately found it well to give cod-liver oil and iron to children even while they are still taking salicylates, and this I believe is worth bearing in mind. Tonsillectomy is thought by many experienced observers to be indicated as a routine measure. The evidence for and against this view is very difficult to appraise, and there is no time to attempt it here. Our own practice is to have tonsils removed if they are obviously diseased, if there is an associated adenitis, or if by reason of their size their removal would be indicated even apart from the coexistence of rheumatic infection. More than once I have seen a serere recrudescence of the infection follow an excision of tonsils which have recently been the seat of an acute inflammation, and it seems, therefore, that anything of this kind should be allowed plenty of time to settle down before operation is advised.

This account of treatment is very unsatisfactory, and seems to amount to nothing more than watching the course of a discase which we are powerless to arrest. Yet I feel sure that much is achieved merely by patience and perseverance in those homely measurcs by which we are accustomed to encourage the fight against bacterial activity. What we need is a clear realization of the tenacity and persistence of this infection. It is not a matter of days or even weeks, but of months or even years. One of the fruits of this attitude of mind is the increased provision for prolonged institutional treatment of these children, but even where this is not essential, or is impracticable, the mere fact that we realize the need for patience and perseverance in the application of an enlightened common sense to the management of this disease is going to make a sensible reduction in the number of cripples for which it is responsible.

REFERENCES.

Shaw, A. F. Bernard: Archives of Disease in Chitdhood, 1929, vol. 4, 155.

2 Perry, C. Bruce : Ibid., 1929, vol. 4, 247.

3 Poynton, F. J.: Rheumatic Heart Disease, by Carey F. Coombs, 1924, Introduction, $x x$.

- Brewer, Dunstan: Archices of Disease in Chillhood, 1928, vol. 3, 277.

- Coombs, Carey F. : Rheumatic Heart Disease, 1924, 269.

\section{An Àntress}

ON

\section{THE DIAGNOSIS OF EARLY JUVENILE RHEUMATISM.*}

REGINALD MILLER, M.D., F.R.C.P.,

PHYSICIAN, AND PHYSICIAN IN CHARGE OF THE RHEUMATISM

SUPERVISORY CENTRE, PADDINGTON GREBN CHILDREN'S HOSPITAL, LONDON.

Juvenile rheumatism is an environmental disease, and until the mass production of it can be stayed by public health measures the best contribution to the problem which can be made by us as individual clinical physicians is to get each separate case of rheumatism in a child diagnosed, treated, and under supervision at the earliest possible stage of the disease. It is to this matter that I now direct attention, and $I$ emphasize at the outset that the diagnosis of early rheumatic infection in a child is at least as difficult a matter as that of early tuberculosis.

Two preliminary questions arise. First, have we a chance of diagnosing rheumatism before serious harm has occurred in the child's heart? Secondly, if we do make such an early diagnosis, have we a sporting chance of preventing serious heart disease?

In answer to the first question it is undoubtedly true that we have a chance of early diagnosis. However abrupt the onset of a serious attack of rheumatism may appear to be-and we all know how rapid, how ruthless, and how overwhelming the onslaught of rheumatic infection can beit is almost invariably the case that premonitory symptoms lrave preceded the attack for weeks or months, and that they have been overlooked, neglected, or misinterpreted. Those who doubt this have not taken their clinical histories correctly; in nearly all cases there is this premonitory stage. And if we make a diagnosis in this premonitory stage, shall we have a chance of preventing more serious attacks, particularly the more serious forms of heart disease? Frankly I do not see why we should doubt it. It is in line with what we do in other diseases. We can remove foci of infection, combat the environmental factors, and protect against exciting-causes of acute attacks. Sometimes we shall fail; perhaps we start too late, perhaps the environment is too heavily against us, perhaps there are factors we cannot control or even recognize, but I see no reason to doubt that often we do really help. Some require mathematical proof of this: they will not get it; you cannot make a statistical comparison of known results with unknown possibilities. The real proof comes to the clinical worker who is supervising his own patients. When he sees, as I have seen in dozens of instances, the removal of tonsils and the adoption of other measures lead to increased weight, strength, and colour, and the gradual loss of rheumatic pains, he will not doubt that in a certain proportion of cases he has actually prevented serious rheumatism and heart disease.

\section{Early Diagnosis.}

Before I come to the study of the prodromal symptoms of juvenile rheumatism there are two factors of possible diagnostic value to be considered-the rheumatic diathesis and the so-called pre-rheumatic child. Are these realities? Can we recognize them? Are they an aid to diagnosis?

\section{The Rheumatic Diathesis.}

Some recent writers have professed great faith in the rheumatic diathesis, in the sense that they think that certain children, if they lose good health, turn naturally into cases of rheumatism. I do not share this view. The older physicians laid great stress upon the familial tendency towards rheumatism, and this rather tended to a belief in a rheumatic diathesis. Recent investigations, undertaken on very accurate and strict lines, show that the family tendency has been exaggerated and is not more than can be accounted for by the frequency of the disease and 
the enrironmental causatire factors. Naturally where a disease is rery common and is powerfully predisposed to by enrironment, its incidence in families will be high. Several points can be adduced against the view that a rheumatic diathesis is of moment. Does a diathesis, for instance, show a class incidence as jurcnile rheumatism does? Again, we must bear in mind the Poor Iaw residential schools. Here thousands of children from the rheumatic stratum of the population in urban districts, in whom there is not the slightest doubt that dozens of cases of rheumatisn would have developed had they been left in their own homes, live ycar in and year out without a case appearing amongst them. How does this happen? Have they left their diatheses at home? Clearly, we need not go in fear of the rheumatic diathesis.

The Pre-rheumatic Child.

As a clinician I have even less liking for the term "pre-rheumatic child" than for the "pre-tuberculous child." These are administrative labels and have little to do with the realities of clinical medicine. It is difficult for us to envisage a condition which is all prognosis and no pathology. However, the term has come into use, and I can only give it as my opinion that the pre-rheumatic child as described is the ordinary rheumatic child, and that there is nothing "pre" about it, save that it has not yet suffered a knock-out attack of the infection. It is in the stage when repeated minor infections are wearing down the child's resistance and so paving the way to a major attack.

Is there, on the other hand, a pre-rheumatic child in the proper sense-namely, a child whose resistance to streptococi is lowered, though not by repeated minor rheumatic infections? The post-scarlatinal child ought perhaps to be reckoned as this, but apart from this cannot say that I can recognize such a child. Some have endearoured to associate intestinal indigestion and toxaemia with future rheumatism, but for my own part $I$ do not consider the case proren. It is true that early case of rheumatism suffer sometimes from intestinal dyspepsia but in my experience the really bad cases of intestina toxaemia are not prone to develop jurenile rheumatism. Nor are, perhaps it is as well to add, the ordinary cases of enlarged tonsils and adenoids.

\section{Premonitory Srmftous.}

I have already said that in most cases of acute rheumatism in children there is a prodromal stage lasting for weeks or months before the onset of serere symptoms and that this is due to the method of invasion by the infecting micro-organism. Both clinically and histologically we have proof that the invasion by rheumatism is by means of repeated minimal infections, which ultimately may wear down the child's resistance and so result in an acute attack. It is the symptoms in this prodromal stage that we now have to study, and for this purpose I define the prodromal stage as that of rheumatic infection before an attack severe enough to send the child to its bed.

Let me emphasize one important aid that wo have to the study of the child in the prodromal stage of rheumatism -namely, the convalescent rheumatic child. As a child recovers from an acute attack it passes back into a condition similar to that it was in during the prodromal stage or stage of inrasion. We cannot therefore study the convalescent child too carefully from this point of view.

In studying the premonitory symptoms of juvenile rheumatism, or rather the child in the prodromal stage of that infection, four groups of symptoms may be usefully described; but I want to make it clear at the outsat that not every child who could be included in any of these four groups is rheumatic, only that it is ont of these groups that you will get your rheumatic cases.

\section{Constitutional Symptoms.}

Jurenile rheumatism is the result of a generalized srstemic infection, but its slighter and earlier srmptoms are for the most part due to a general rhcumatic toxaemia. Consequently there is a condition of general constitutional ill health, not in itself very specific or diagnostic, but recognizable by its association with the rheumatic symptoms to be described later. The chief importance of this state of ill health, and the reason why it must be carefully studied, is that, unless the occurrence of definite rheumatic symptoms is inquired into, it may easily be mistaken for some other condition.

The rheumatic child is pale, rather sallow, and unhealthy in appcarance. Its most prominent symptom is its tiredness. Its appetite is poor, its nerves irritable, its sleep not too good. Often it is a little short of breath, and may have a throat cough. Its temperature and pulse rate may be raised by evening. Perhaps the only thing characteristic about its appearance is the flush which appears on the cheeks in a hot room; there is in this a rather typical maure tinge in the pink flush.

Now a child who looks toxic, who is pale, tired, off its food, and rumning a little fever at night, is not un!ikely to be regarded as tuberculous. Add to these symptoms a cough from the presence of septic tonsils, and slight shortness of breath from myocardial poisoning, and the similarity to the symptoms of early pulmonary tuberculosis becomes cren greater. It must be emphasized that the symptoms which in a young adult should suggest the possibility of consumption do not necessarily, or even usually, mean the same in a child. This is important, for although it is bad for a rhcumatic child to remain undiagnosed, it is still worse for it to be diagnosed as tuberculous. The diagnosis between the two types of child is not as a rule difficult: the appearance of a rheumatic child is very different from that of a tuberculous child, and in cases of difficulty the occurrence of typical rheumatic pains may be a decisive point.

\section{Throats and Pains Group.}

This is the most easily rocognizable group. Sore throats are common enough in rheumatic children, but they may be absent whare the tonsils are small and buried-a type which is associated in my mind with ultimate mitial stenosis. Not much is heard in children of the persistently uncomfortable throat, such as is complained of by adults with sep!ic buried tonsils. Of much more importance than the symptom of sore throat are the signs of tonsillar infection. Septic tonsils are present in 80 to 80 per cent. of rhoumatic childien, and spontaneons cure in them is very exceptional. In $m y$ own cases not 5 per cent. of tonsils thought at one time to be infected have later been passed as normal, and these would consist chiefly of cxamples of acute tonsillitis.

What critcria shall we adopt as indications of chronic tonsillar sepsis? It is worth while spending a moment on this matter. (1) The size of the tonsil does not matter. The tonsils in rhemmatic children are scldom rery large, and do not often cause real obstruction; indeed, they may be very small and buried. (2) The surface of the tonsils is red in acute phases, and cryptic and irregular in chronic cases. (3) The faucial pillars show crescentic arcas of red where they cover the buried parts of the tonsils. (4) The tonsillar glinds at the angles of the jaw are enlarged. (5) Purulent material can be squeezed from the mouths of the crypts.

These signs are not all of equal value. I do not know, for instance, that wo have any right to insist that the tonsillar glands should always be enlarged in rheumatic tonsillitis, for we are well aware that lrmphatic glands in rheumatism do not swell and to not seem to put up any barrier to the infection. Again, I do not personally know how much stress should be laid upon the appearance of purrulent material from the crypts when the tonsil is squeezed; does it necessarily mean a chronic infection capable of harming the child? Therefore I lay the greatest stress on the reddening of the faucial pillars. This last is applicable to the buried as well as to the visible tonsil; it stows infection of the hidden part of the tonsil, and it means that that infection is active and sufficiently virulent to be producing a reaction outside the tonsil, and so is presumably capable of poisoning the ehild to some degree.

Rheumatic pains are so well known that they may be considered bricfly. Their characteristics are that they occur in the neighbourhood of joints, that they are made 
better by rest and worse by exercise, and that they may be acconipanied by siight ferer. They may be sharp or more in the nature of a dull aching pain. We cannot possibly maintain that all muscular pains in children are truly sheumatic. Delicate nervous children with intestinal toxacinia, acidosis, and vasomotor disturbances get similar pains, and therefore in diagnosis the whole picture of the 'hild has to be taken into consideration. Pains in the arms, wrists, and fingers are usually rheumatic; and the saise may be said of stiff neck, in the absence of enlarged glands.

In this group with sore throats and pains a certain number of children will develop serious rheumatism, usually arthritis and heart disease, with perhaps nodules. The association between tonsillitis and chorea is less close than that between tonsillitis and arthritis.

\section{The Nervous Group.}

Rheumatism is a nerve poison. When it damages the hrain with sufficient severity, by toxacmia or infection, we get the syndrome which we know as chorea; but long before this condition is reached there is clinical evidence that tho nervous system is affected in rheumatism. No child with any degree of rheumatism fails to show some srmptoms referable to the brain; there is much truth in the saving attributed to a physician of the last generation that "all rheumatic children have chorea; only some more so." For this condition I suggested many years ago the term " latent chorea."

The fundamental change which occurs is that of general nervous instability. The child becomes sharpened up; it is cuick, responsive, excitahle, emotional, and easily depressed or excited. It smiles at you readily and its hands are rather fidgety. These attributes make it rery friendly and explain why the rheumatic children are so popular in hospital.: They also explain why such children do so badly at convalescent homes.

kingrafted on this gencral nervous instability of rheumatic origin may be other disorders which we usually class as functional-sleeplessness, sleep-walking, night terrors, nocturnal enuresis, tics, and so on; and the point which I wish to make is that a certain number of rheumatic children will come first under observation on account of such disorders; or, put the other way round, a proportion of rases secking treatment for various functional nerrous disorders will be instances of rheumatic infection.

The association between rheumatism and general nerrousness. is well recognized. I used to be taught that nerrous children were particularly prone to rheumatism. I am sure this is the wrong way round: a child does not become rheumatic because it is nervous, it becomes nervous because it is rheumatic. There are, of course, many children who conform to this group who are not rheumatic; nevertheless it is out of this group that many cases of rheumatie infection, chiefly chorea, will develop.

\section{The Cardiac Group.}

I come now to the consideration of those signs in a heart which make one suspect rheumatic infection. Sometimes, as we all know, in an individual case the condition of the heart is the one and only diagnostic proof of rheumatism. More often we search the heart for signs of rheumatism to confirm a suspicion of the presence of the disease. In examining the heart of a child for such evidence it is absolutely essential that the examinations should be made when the patient is lying down as well as when he is standing up. Frequently, too, it is well to auscultate the heart with the child lying on its left side.

The signs suspicious of rheumatic heart disease, starting with the least important, are as follows: (1) Increased pulse rate. This is of no diagnostic value unless accompanied by (2) dilatation of the left ventricle-that is, the apex is outside the nipple line. Such a condition probably means the presence of myocarditis, and is therefore suspicious of rheumatism. (3) If with enlargement of the left rentricle there is an apical systolic murmur, audible in any of the postures already mentioned and clearly not a cardio-respiratory bruit, the diagnosis of rheumatism is practically certain. (4) The presence of a reduplicated apical second sound, or of a mid-diastolic apical murmur, is also good evidence of rhemmatism. This "third sound," as it is called, requires careful listening for; it is audible over a very small area intcrnal to the apex beat, and is usually more clearly heard when the child is lying down than when it is standing.

In addition to these changes, which are the ordinary ones found in early rheumatic heart disease, there are certain cases of rheumatism which present themselves as examples of persistent tachycardia. In such instances it may be rery difficult to distinguish the neurotic from tho toxaemic group, and it is therefore woll to remember that certain of the cases of persistent tachycardia met in children will ultimately be found to be of rbeumatic origin.

\section{Summary.}

Now I have been through most of the carly signs and symptoms of rheumatic infection in a child. It will he seen that they are very various, and for the most part slight and rather indefinite. It is this that makes the diagnosis of early rheumatism difficult. It can only be reached by the due consideration of all the signs and symptoms. Where there are several such, cven though each one separately is no more than suspicions, a positive diagnosis may be reached with some certainty. For my own part I think the diagnosis is most easily reached in two stages: first, by a consideration of the general appearance and deportment of the child, of ten enough very characteristic to one familiar with rheumatic children; secondly, by a detailed consideration of the various signs and symptoms, including a careful examination of the heart.

\section{RADIUM TELETHERAPY.}

Note on the Apparates at Present in Use at the Westminster Hospital with Four Grams of Raditm.*

BY

FRANCIS ROCK CARITNG, B.Sc.TOND.,

TECINICAL ADVISER FOR RADIUM WORK, WESTMINSTER HOSPITAL.

The apparatus to be describer was designed at the Westminster Hospital to meet the problem of making the most effective though economical use of the 4 grams of national radium that had been lent to the hospital for use as a " bomb," and, at the same time, of protecting from the emanations all persons except those actually under treatment.

The difficulties of affording proper protection were much simplified by housing the bomb in one of the theatres, which happens to be so situated that below it is a stairway, while above there is an open space, and on each side are two main walls and an area that must be traversed before reaching the wards. It was then anticipated that, by limiting the radiation to an approximately vertical direction, complete safety would be assured. Subsequent investigation by the usual electroscope method showed that the amount of radiation that could be received from the bomb by anyone in the hospital, other than those attending in the bomb room, had no biological significance.

The apparatus is constructed so that two patients may be treated simultaneously, one above and one beneath the radium container (Fig. 1). The lower stretcher is placed ais close to the ground as is convenient in order that the upper stretcher shall not be so high as to offer great difficulty of access. Wach stretcher can be raised, lowered, and traversed longitudinally and laterally, and the lower stretcher can be tilted as well. The stretchers run on wheels, and can easily be moved to and from the bomb.

The radium is held in twenty containers arranged in four groups of five; each group can be withdrawn from use, if required, by pulling the appropriate knob provided outside the bomb (Fig. 2). When not required the radium is all withdrawn so that it is buried in lead. The average protection provided, whether the radium is in use or withdrawn, amounts to some six inches of lead in the horizontal plane, and, when withdrawn, to three inches on the neutral axis. When the apparatus is in use the radium sources are 